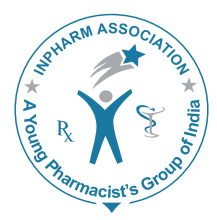

\title{
High productivity pharmaceutical organizations in India: A study of their performance during 2008-12
}

\author{
Ritu Gupta', KK Mueen Ahmed², BM Gupta ${ }^{3 *}$ \\ ${ }^{1}$ Sri Venkateshwar University, Meerut, Uttar Pradesh, India, ${ }^{2}$ Phcog.Net and SciBiolMed, Bangalore, \\ Karnataka, India, ${ }^{3}$ Panchkula, Haryana, India
}

\begin{abstract}
The paper analyses high productivity organizations in pharmaceutical science in India, using the publications data indexed and covered in Scopus database from 2008 to 2012. It identified their overall strength of these pharmaceutical organizations, measured in terms of select quantitative and qualitative indicators. It also provides a comparative evaluation and performance of different types of Indian pharmaceutical organizations. The study concludes that institutes of research institutes, institutes of national importance and universities model of funding for research are comparatively more effective in giving performance in terms of quantity and quality. The paper also lists suggestions for national policy formulation for growth and development of pharmaceutical research in the country.
\end{abstract}

Key words: Bibliometric indicators, high productivity organizations, India, pharmcology, performace, scientometrics

\section{INTRODUCTION}

Pharmacology is one of the main disciplines under biomedical science and the pharmaceutical industry. There are many disciplines within the biomedical sciences. Pharmacy is related to health sciences. It is the profession responsible for the preparation, dispensing and appropriate use of medication and which provides services to achieve optimal therapeutic outcomes. A pharmacists job is to prepare, mix, compound or dispense drugs and medicines, ointments, powder, pills, tablets and injections

\begin{tabular}{|c|c|}
\hline \multicolumn{2}{|c|}{ Access this article online } \\
\hline Journal Sponsor & \multirow[b]{2}{*}{$\begin{array}{l}\text { Website: } \\
\text { www.jyoungpharm.org }\end{array}$} \\
\hline \multirow{2}{*}{ www.phcog net } & \\
\hline & $\begin{array}{l}\text { DOI: } \\
\text { 10.5530/jyp.2014.2.2 }\end{array}$ \\
\hline
\end{tabular}

on the prescription of a medical practitioner, dentist or veterinarian. In detail, they are concerned with production of pharmaceutical products, development of the methods or processes of production and quality control. Those in research concern themselves with synthesis of new drugs (what is commonly referred to as molecules), new processes, clinical testing of the effects of such drugs on animals and humans, and obtaining the required license from the drug control authorities. A pharmacist is required to explain the mode and precautions regarding the use of medicines dispensed in a hospital pharmacy, prepare special formulations normally not available in the market, assist the physician in rendering necessary information about various drugs, their contra-indications, incompatibility etc.

There are over 225 programs in pharmacy conducted by different universities in India. The main courses in pharmacy are the 2 years Diploma in Pharmacy (D.Pharm), 4 years Bachelor of Pharmacy (B.Pharm), 2 years Master 
of Pharmacy (M.Pharm) and Ph.D programs. The main courses in pharmacy are the 2 years D.Pharm, 4 years B.Pharm, 2 years M.Pharm and Ph.D programs. Admission to the D.Pharm, requires a pass in $10+2$ or equivalent examination with Physics, Chemistry, Maths (PCM) or Biology. Candidates who possess $10+2$ with PCM or PCB or Ph PCM and Biology are admitted to the 4-year bachelors program level (Bachelor of Pharmacy or B.Pharm). At Bachelor level there is no specialization. At the masters level (M.Pharm) specialization is available in Pharmaceutics, Pharmacognosy, Pharmaceutical Chemistry, Biochemistry, Pharmaceutical Engineering etc. and after M.Pharm candidates can go for Ph.D program in Pharmaceutics, Pharmaceutical Chemistry, Pharmacology, Pharmaceutical Marketing and Management. Some institutions conduct their own entrance test for admission to B.Pharm courses. Main entrance exams for admissions to pharmacy courses are state wise entrance exams, All India Engineering Entrance Examination (for degree courses) Graduate Aptitude Test in Engineering (post-graduation) etc. Institutions like Indian Institute of Technology (IIT) and some other institutions also accept the score of these entrance exams. After obtaining a diploma or degree in pharmacy, and registering with the state Pharmacy Council, it is possible set up your own pharmacy or chemists and druggists shop to stock and sell medicines and dispense them according to doctor's prescription. Personal qualities: In order to be a successful pharmacist, one must have a liking for science particularly life sciences and medicine. An ability to put hard work, strong logical thinking, patience, a sense of responsibility, patient counseling skills is some of the qualities needed for pharmacist. Strong analytical abilities and strong academic foundations are needed in the field of research. To be a successful medical representative, one needs to have good communication skills and a flair for convincing people, retail pharmacists need to have business skills together with good product knowledge. ${ }^{1}$

A few evaluative studies have been carried out in the past on contribution and impact of pharmacological research measured in terms of publications output. Ahila and Nagarajan ${ }^{2}$ analysis 22,065 global publications in pharmaceutical research, deriving publication data from Web of Science database during 1999-2010 (12 years). It analysis the global publication growth, share and rank of top 15 most productive countries, authorship pattern, identification of high productive institutions and journals. Har Kaur and Gupta ${ }^{3}$ examines India's performance in pharmacacology, using Scopus database during 1998-2007, based on several parameters, such as global publication share and rank of top 15 most productive countries, India's publication growth, citation impact and international collaborative share, institutional profile of select leading institutions, pattern of communication and contribution and impact of most productive authors, etc. Gupta and Har Kaur et al. ${ }^{4}$ analysis ranking of most productive Indian institutions in pharmacology for their research output during 2000-2009. Their output is judged on the basis of few quantitative and qualitative indicators.

\section{Objectives}

The paper studies the performance of top 110 high productivity Indian institutions in pharmaceutical science by using quantitative and qualitative indicators to understand their comparative strength and weakness. The study also examines how different models of institutional funding influence performance in pharmaceutical research in India.

\section{METHODOLOGY}

The study is based on raw bibliographic publication data (along with data on other parameters) for the period of 5 years from 2008 to 2012, extracted and downloaded from Scopus international multidisciplinary database in November 2013. The citations received by papers are considered for first 3 years (3-year citation window). The institutional performance was measured on the number of quantitative and qualitative indicators, such as the number of papers, average citation per paper (ACPP), h-index (HI) and share of international collaborative papers (ICP) and share of high cited papers (HCP). Based on different models of funding, the high productivity institutions are classified as institutes of national importance (INIs), universities, research institutes, engineering colleges, pharmaceutical schools and colleges, medical colleges and hospitals and industrial enterprises. These institutional models of funding differ significantly in terms of strength, number of researchers they employed and the papers published by each.

\section{Analysis of top 110 most productive organizations engaged in pharmaceutical research}

The top 110 most productive organizations engaged in pharmaceutical research comprises of 25 universities, 23 research institutes, 12 INIs, 17 pharmacy schools and colleges, 16 medical colleges and hospitals, eight engineering colleges and nine industrial firms. These 110 organizations together contributed 28,660 papers, accounting for $54.44 \%$ share of total pharmaceutical research in India during 2003-2012. The top 110 most productive organizations involved in pharmacological research have published from 31 to 1467 papers each 
during 2003-2012. The average publication productivity per organization reported by the top 110 Indian organizations was 260.54 and only 34 organizations have registered higher output than the group average. The ACPP registered by the total papers (TP) of these 110 Indian organizations engaged in pharmaceutical research was 3.72 (varying from 0.66 to 7.61 ) during 2003-2012 and 42 organizations have registered higher citation impact than the group average. The average HI registered by the TP of these 110 Indian organizations engaged in pharmaceutical research was 22.43 (varying from 5 to 57) during 2003-2012 and 53 organizations have registered higher $\mathrm{HI}$ than the group average. The average share of ICP registered by the 110 Indian organizations engaged in pharmaceutical research was $10.11 \%$ (varying from $0 \%$ to $51.61 \%$ ) during 2003-2012 and 44 organizations have registered higher share of ICP than the group average. The average share of HCP registered by the 110 Indian organizations engaged in pharmaceutical research was $0.59 \%$ (varying from $0 \%$ to $3.57 \%$ ) during 2003-12 and 30 organizations have registered higher share of HCP than the group average.

\section{Universities}

The top 25 most productive Indian universities involved in pharmacological research have published from 226 to 1092 papers each during 2003-2012. These 25 Indian universities together have contributed $23.11 \%$ (12165 papers) in the cumulative publications output of India in pharmacological research. The publication profile of these 25 Indian universities along with their research output, citations received and $\mathrm{HI}$ values are presented in Table 1 . The average publication productivity per university reported by the top 25 Indian universities was 486.6 and only 18 universities have registered higher output than the group average. These are Indian Jamia Hamdard, Delhi (1092 papers), followed by Annamalai University (969 papers), Dr. Harisingh Gour University, Sagar (908 papers), Panjab University, Chandigarh (830 papers), Jadavpur University, Kolkata (804 papers), University of Madras (743 papers), Andhra University (592 papers) and MS University of Baroda (535 papers).

The ACPP registered by the TP of these 25 Indian universities was 3.56 (varying from 1.49 to 5.46) during 2003-2012 and 12 universities have registered higher citation impact than the group average. They are University of Delhi with a citation impact per paper of 5.46, followed by Guru Nanak Dev University, Amritsar (5.08), Dr. Harisingh Gour University, Sagar (5.01), Banaras Hindu University, Varanasi (4.99), University of Madras (4.54), Panjab University, Chandigarh (4.47), Punjabi University,
Patiala (4.18), Jamia Hamdard, Delhi (3.90), Aligarh Muslim University (3.88), University of Pune (3.87), Mumbai University Institute of Chemical Technology, Mumbai (3.73) and Jadavpur University (3.71).

The average HI registered by these 25 Indian universities was 30.68 (varying from 13-50) during 2003-2012 and 9 universities have registered higher HI value than the group average. They are Jamia Hamdard, Delhi with a HI value of 50, followed by Dr. Harisingh Gour University, Sagar (48), Panjab University, Chandigarh (48), University of Madras (43), Jadavpur University, Kolkata (43), Annamalai University (41), University of Delhi (35), MS University of Baroda (933), and Banaras Hindu University (31).

The average share of ICP achieved by 35 Indian universities in pharmacological research was $10.88 \%$ (varying from $3.01 \%$ to $27.60 \%$ ) during 2003-2012 and 14 universities have achieved higher share of ICP than the group average. They are University of Delhi with ICP share of 27.60. followed by Sri Venkateswar University, Tirupati (20.50\%), Aligarh Muslim University (19.02\%), University of Lucknow (18.46\%), University of Pune (15.72\%), Jamia Hamdard, Delhi (14.38\%), Mumbai University Institute of Chemical Technology (14.34\%), Kakatia University (13.20\%), University of Calcutta (13.02\%), Banaras Hindu University, Varanasi (12.93\%), University of Mysore (12.89\%), Andhra University (12.16\%), Bharati Vidyapeeth University, Pune (11.61) and Guru Nanak Dev University, Amritsar (11.36\%).

The average share of HCP achieved by 25 Indian universities in pharmacological research was 0.56 (varying from $0.0 \%$ to $1.58 \%$ ) during $2003-2012$ and 9 universities have achieved higher share of HCP than the group average. They are University of Delhi with HCP share of $1.58 \%$, followed by Panjab University, Chandigarh (1.33\%), Jadavpur University, Kolkata (1.24\%), Dr. Harisingh Gour University, Sagar (1.10\%), B Mumbai University Institute of Chemical Technology (0.75\%), Jamia Hamdard (0.64\%), Aligarh Muslim University $(0.58 \%)$, Banaras Hindu University $(0.57 \%)$ and University of Mysore (0.57\%).

\section{Research institutes}

The top 23 Indian research institutes involved in pharmacological research have published from 82 to 1467 papers each during 2003-2012. These 23 Indian research institutes involved together have contributed 13.24\% (6971 papers) in the cumulative publications output of India in pharmacological research. The publication profile of these 23 Indian research institutes along

Journal of Young Pharmacists Vol 6 • Issue 2 • Apr-Jun 2014 
Table 1: Scientometric profile of top 25 universities in pharmacology, 2008-2012

\begin{tabular}{|c|c|c|c|c|c|c|c|c|}
\hline Name of the university & TP & TC & ACPP & HI & ICP & \%ICP & HCP & $\% \mathrm{HCP}$ \\
\hline Jamia Hamdard, Delhi & 1092 & 4256 & 3.90 & 50 & 157 & 14.38 & 7 & 0.64 \\
\hline Annamalai University & 969 & 3084 & 3.18 & 41 & 57 & 5.88 & 3 & 0.31 \\
\hline Dr. Harisingh Gour University, Sagar & 908 & 4547 & 5.01 & 48 & 63 & 6.94 & 10 & 1.10 \\
\hline Panjab University, Chandigarh & 830 & 3709 & 4.47 & 48 & 54 & 6.51 & 11 & 1.33 \\
\hline Jadavpur University, Kolkata & 804 & 2986 & 3.71 & 43 & 75 & 9.33 & 10 & 1.24 \\
\hline University of Madras & 743 & 3373 & 4.54 & 43 & 66 & 8.88 & 2 & 0.27 \\
\hline Andhra University & 592 & 899 & 1.52 & 27 & 72 & 12.16 & 1 & 0.17 \\
\hline MS University of Baroda & 535 & 1759 & 3.29 & 33 & 38 & 7.10 & 1 & 0.19 \\
\hline Kakatiya University & 447 & 1133 & 2.53 & 30 & 59 & 13.20 & 2 & 0.45 \\
\hline University of Rajasthan, Jaipur & 444 & 764 & 1.72 & 24 & 19 & 4.28 & 0 & 0.00 \\
\hline University of Delhi & 442 & 2412 & 5.46 & 35 & 122 & 27.60 & 7 & 1.58 \\
\hline Jawaharlal Nehru Technological University, Hyderabad & 430 & 858 & 2.00 & 19 & 30 & 6.98 & 0 & 0.00 \\
\hline Bharati Vidyapeeth University, Pune & 379 & 967 & 2.55 & 30 & 44 & 11.61 & 2 & 0.53 \\
\hline University of Calcutta & 361 & 1272 & 3.52 & 22 & 47 & 13.02 & 2 & 0.55 \\
\hline University of Mysore & 349 & 1079 & 3.09 & 25 & 45 & 12.89 & 2 & 0.57 \\
\hline Banaras Hindu University, Varanasi & 348 & 1736 & 4.99 & 31 & 45 & 12.93 & 2 & 0.57 \\
\hline Aligarh Muslim University & 347 & 1348 & 3.88 & 29 & 66 & 19.02 & 2 & 0.58 \\
\hline Punjabi University, Patiala & 332 & 1388 & 4.18 & 27 & 10 & 3.01 & 1 & 0.30 \\
\hline Sri Venkateswar University, Tirupati & 317 & 775 & 2.44 & 21 & 65 & 20.50 & 0 & 0.00 \\
\hline Mumbai University Institute of Chemical Technology & 265 & 989 & 3.73 & 25 & 38 & 14.34 & 2 & 0.75 \\
\hline Guru Nanak Dev University, Amritsar & 264 & 1341 & 5.08 & 29 & 30 & 11.36 & 0 & 0.00 \\
\hline University of Lucknow & 260 & 680 & 2.62 & 23 & 48 & 18.46 & 0 & 0.00 \\
\hline RTM Nagpur University & 252 & 681 & 2.70 & 24 & 25 & 9.92 & 1 & 0.40 \\
\hline University of Pune & 229 & 887 & 3.87 & 27 & 36 & 15.72 & 0 & 0.00 \\
\hline Osmania University & 226 & 337 & 1.49 & 13 & 12 & 5.31 & 0 & 0.00 \\
\hline Total & 12165 & 43260 & 3.56 & 30.68 & 1323 & 10.88 & 68 & 0.56 \\
\hline Total of the country & 52645 & & & & & & & \\
\hline Share of top 25 universities in India's total & 2311 & & & & & & & \\
\hline
\end{tabular}

TP: Total papers, TC: Total citations, ICP: International collaborative papers, HCP: High cited papers, HI: h-index

with their research output, citations received and HI values are presented in Table 2 . The average publication productivity per institute reported by the top 23 research institutes was 303.09 and only 5 research institutes have registered higher output than the group average. These are Indian Institute of Chemical Technology (IICT), Hyderabad with 1467 papers, followed by Central Drug Research Institute (CDRI), Lucknow (1011 papers), National Institute of Pharmaceutical Education and Research (NIPER), Mohali (817 papers), National Chemical Laboratory (NCL), Pune (444 papers) and Indian Institute of Toxicological Research (IITR), Lucknow (437 papers).

The ACPP registered by the TP of these 23 research institutes was 5.02 (varying from 2.17 to 7.61 ) during 2003-2012 and nine research institutes have registered higher citation impact than the group average. They are Center for Cellular and Molecular Biology (CCMB) (7.61), followed by Indian Association for Cultivation of Science (IACS), Kolkata (6.61), Central Leather Research Institute (CLRI), Chennai (6.60), Bose Institute, Kolkata (6.07), Institute of Genomics and Integrated Biology, Delhi (6.07),
IITR, Lucknow (5.84), IICT, Hyderabad (5.50), NIPER, Mohali (5.44) and NCL, Pune (5.41).

The average $\mathrm{HI}$ registered by these 23 research institutes was 27.96 (varying from 11 to 57) during 2003-2012 and nine research institutes have registered higher $\mathrm{HI}$ value than the group average. They are IICT, Hyderabad with a HI value of 57, followed by NIPER, Mohali (55), CDRI, Lucknow (45), NCL, Pune (38), IITR, Lucknow (35), Indian Institute of Chemical Biology (IICB), Kolkata (29), National Botanical Research Institute (NBRI), Lucknow (29), CLRI, Chennai (28) and Bhabha Atomic Research Center, Mumbai (28).

The average share of ICP achieved by 25 research institutes involved in pharmacological research was $10.07 \%$ (varying from $4.43 \%$ to $27.38 \%$ ) during 2003-2012 and nine research institutes have achieved higher share of ICP than the group average. They are CCMB, Hyderabad with ICP share of 27.38 followed by IICB, Kolkata (16.38\%), NIPER, Mohali (14.69\%), IITR, Lucknow (13.50\%), Indian Veterinary Research Institute (IVRI), Izatnagar (12.82\%), IACS, Kolkata (12.14\%) and Bhabha Atomic Research Center (BARC), Mumbai (11.36\%). 
Table 2: Scientometric profile of top 23 research institutes in pharmacology, 2008-2012

\begin{tabular}{|c|c|c|c|c|c|c|c|c|}
\hline Name of the research institutes & TP & TC & ACPP & HI & ICP & \%ICP & HCP & $\% \mathrm{HCP}$ \\
\hline IICT, Hyderabad & 1467 & 8066 & 5.50 & 57 & 118 & 8.04 & 7 & 0.48 \\
\hline CDRI, Lucknow & 1011 & 4645 & 4.59 & 45 & 81 & 8.01 & 6 & 0.59 \\
\hline NIPER, Mohali & 817 & 4444 & 5.44 & 55 & 120 & 14.69 & 22 & 2.69 \\
\hline NCL, Pune & 444 & 2401 & 5.41 & 38 & 37 & 8.33 & 6 & 1.35 \\
\hline IITR, Lucknow & 437 & 2550 & 5.84 & 35 & 59 & 13.50 & 4 & 0.92 \\
\hline IICB, Kolkata & 293 & 1411 & 4.82 & 29 & 48 & 16.38 & 2 & 0.68 \\
\hline BARC, Mumbai & 273 & 1156 & 4.23 & 28 & 31 & 11.36 & 4 & 1.47 \\
\hline IIIM, Srinagar & 220 & 1071 & 4.87 & 23 & 13 & 5.91 & 1 & 0.45 \\
\hline NBRI, Lucknow & 198 & 686 & 3.46 & 29 & 13 & 6.57 & 2 & 1.01 \\
\hline CLRI, Chennai & 182 & 1201 & 6.60 & 28 & 17 & 9.34 & 2 & 1.10 \\
\hline CIMAP, Lucknow & 180 & 573 & 3.18 & 19 & 15 & 8.33 & 1 & 0.56 \\
\hline IACS, Kolkata & 173 & 1143 & 6.61 & 26 & 21 & 12.14 & 3 & 1.73 \\
\hline DRDE, Gwalior & 158 & 696 & 4.41 & 24 & 7 & 4.43 & 1 & 0.63 \\
\hline IVRI, Izatnagar & 156 & 468 & 3.00 & 19 & 20 & 12.82 & 2 & 1.28 \\
\hline INMAS, New Delhi & 152 & 592 & 3.89 & 24 & 12 & 7.89 & 0 & 0.00 \\
\hline IGIB, Delhi & 130 & 789 & 6.07 & 27 & 13 & 10.00 & 0 & 0.00 \\
\hline CFTRI, Mysore & 116 & 447 & 3.85 & 22 & 13 & 11.21 & 0 & 0.00 \\
\hline BI, Kolkata & 113 & 686 & 6.07 & 25 & 15 & 13.27 & 1 & 0.88 \\
\hline IARI, New Delhi & 105 & 228 & 2.17 & 11 & 8 & 7.62 & 0 & 0.00 \\
\hline IHBT, Palampur & 90 & 337 & 3.74 & 17 & 4 & 4.44 & 0 & 0.00 \\
\hline CSMCRI, Bhavnagar & 90 & 442 & 4.91 & 21 & 6 & 6.67 & 0 & 0.00 \\
\hline CCMB, Hyderabad & 84 & 639 & 7.61 & 22 & 23 & 27.38 & 3 & 3.57 \\
\hline CNCI, Kolkata & 82 & 346 & 4.22 & 19 & 8 & 9.76 & 0 & 0.00 \\
\hline Total & 6971 & 35017 & 5.02 & 27.96 & 702 & 10.07 & 67 & 0.96 \\
\hline Total of the country & 52645 & & & & & & & \\
\hline Share of top 23 research institutes in India's total & $13.24 \%$ & & & & & & & \\
\hline
\end{tabular}

TP: Total papers, TC: Total citations, ICP: International collaborative papers, HCP: High cited papers, HI: h-index, IICT: Indian Institute of Chemical Technology, CDRI: Central Drug Research Institute, NIPER: National Institute of Pharmaceutical Education and Research, NCL: National Chemical Laboratory, IITR: Indian Institute of Toxicological Research, IICB: Indian Institute of Chemical Biology, BARC: Bhabha Atomic Research Centre, IIIM: Indian Institute of Integrated Medicine, NBRI: National Botanical Research Institute, CLRI: Central Leather Research Institute, CIMAP: Centre for Medicinal Plants Research, IACS: Indian Association for Cultivation of Science, DRDE: Defense Research and Development Establishment, IVRI: Indian Veterinary Research Institute, INMAS: Institute of Nuclear Medicine and Allied Sciences, IGIB: Institute of Genomics and Integrated Biology, CFTRI: Central Food Technological Research Institute, BI: Bose Institute, IARI: Indian Agricultural Research Institute, IHBT: Institute of Himalayan Bioresource Technology, CSMCRI: Center for Salt and Marine Chemicals Research Institute, CCMB: Centre for Cellular and Molecular Biology, CNCl: Chittaranjan National Cancer Institute

The average share of HCP achieved by 23 Indian research institutes in pharmacological research was 0.96 (varying from $0.0 \%$ to $3.57 \%$ ) during $2003-2012$ and eight organizations have achieved higher share of HCP than the group average. They are CCMB, Hyderabad with HCP share of 3.57, followed by NIPER, Mohali (2.69\%), IACS, Kolkata (1.73\%), BARC, Mumbai (1.47\%), NCL, Pune (1.35\%), IVRI, Izatnagar (1.28\%), CLRI, Chennai $(1.10 \%)$, and NBRI, Lucknow (1.01).

\section{Institute of national importance}

The top 12 Indian INIs involved in pharmacological research have published from 87 to 614 papers each during 2003-2012. These 12 Indian INIs involved together have contributed 5.10\% (2686 papers) in the cumulative publications output of India in pharmacological research. The publication profile of these 12 INIs along with their research output, citations received and HI values are presented in Table 3. The average publication productivity per institute reported by the 12 Indian INIs was 223.83 and only four institutes have registered higher output than the group average. These are All India Institute of Medical Sciences, New Delhi with 614 papers, followed by Indian Institute of Science, Bangalore (361 papers), Postgraduate Institute of Medical Education and Research (PGIMER), Chandigarh (312 papers) and IIT, Kharagpur (238 papers).

The ACPP registered by the TP of these 12 INIs was 4.24 (varying from 1.81 to 7.01) during 2003-2012 and 8 institutes have registered higher citation impact than the group average. They are IIT, Madras with ACPP of 7.01, followed by IIT, Guwahati (6.67), IIT, Bombay (5.53), IIT, Kanpur (5.44), Indian Institute of Science, Bangalore (4.88), IIT, Delhi (4.70). IIT, Kharagpur (4.52) and IIT, Roorkee (4.39).

The average HI registered by these 12 INIs was 24.42 (varying from 15 to 36) during 2003-2012 and eight institutes have registered higher HI value than the group average. They are All India Institute of Medical Sciences, 
Gupta, et al.: High productivity pharmaceutical organizations in India

Table 3: Scientometric profile of top 12 Indian institute of national importance in pharmacology, 2008-2012

\begin{tabular}{|c|c|c|c|c|c|c|c|c|}
\hline Name of the institutes & TP & TC & ACPP & HI & ICP & \%ICP & HCP & $\% \mathrm{HCP}$ \\
\hline All India Institute of Medical Sciences, New Delhi & 614 & 1828 & 2.98 & 36 & 63 & 10.26 & 4 & 0.65 \\
\hline IIIS, Bangalore & 361 & 1762 & 4.88 & 27 & 17 & 4.71 & 0 & 0.00 \\
\hline PGIMER, Chandigarh & 312 & 976 & 3.13 & 26 & 25 & 8.01 & 1 & 0.32 \\
\hline IIT, Kharagpur & 238 & 1076 & 4.52 & 26 & 33 & 13.87 & 1 & 0.42 \\
\hline IIT, Kanpur & 188 & 1023 & 5.44 & 27 & 11 & 5.85 & 2 & 1.06 \\
\hline IIT, Bombay & 186 & 1028 & 5.53 & 25 & 44 & 23.66 & 1 & 0.54 \\
\hline JIPMER, Pondicherry & 162 & 293 & 1.81 & 17 & 15 & 9.26 & 0 & 0.00 \\
\hline IIT, Madras & 147 & 1030 & 7.01 & 27 & 16 & 10.88 & 0 & 0.00 \\
\hline IIT, Delhi & 142 & 667 & 4.70 & 20 & 17 & 11.97 & 0 & 0.00 \\
\hline IIT, Roorkee & 138 & 606 & 4.39 & 22 & 25 & 18.12 & 0 & 0.00 \\
\hline IIT, Guwahati & 111 & 740 & 6.67 & 25 & 9 & 8.11 & 0 & 0.00 \\
\hline NIMANS, Bangalore & 87 & 358 & 4.11 & 15 & 23 & 26.44 & 2 & 2.30 \\
\hline Total & 2686 & 11387 & 4.24 & 24.42 & 298 & 11.09 & 11 & 0.41 \\
\hline Total of the country & 52645 & & & & & & & \\
\hline Share of top 13 INS in India's total & 5.10 & & & & & & & \\
\hline
\end{tabular}

New Delhi with HI value of 36, followed by IIT, Madras (27), IIT, Kanpur (27), Indian Institute of Science, Bangalore (27), IIT, Kharagpur (26), PGIMER, Chandigarh (26), IIT, Guwahati (25) and IIT, Bombay (25).

The average share of ICP achieved by 12 INIs involved in pharmacological research was $11.09 \%$ (varying from $4.71 \%$ to $26.44 \%$ ) during $2003-2012$ and five institutes have achieved higher share of ICP than the group average. They are National Institute of Mental Health and Allied Sciences (NIMANS), Bangalore (26.44\%), IIT, Bombay (23.66\%), IIT, Roorkee (18.12\%), IIT, Kharagpur (13.87\%) and IIT, Delhi (11.97\%).

The average share of HCP achieved by 12 INIs in pharmacological research was 0.41 (varying from $0.0 \%$ to $2.30 \%$ ) during $2003-2012$ and five organizations have achieved higher share of HCP than the group average. They are NIMANS, Bangalore with HCP share of 32.30\%, followed by IIT, Kanpur (1.06\%), All India Institute of Medical Sciences, New Delhi (0.65\%), IIT, Bombay (0.54\%) and IIT, Kharagpur (0.42\%).

\section{Pharmacy schools and colleges}

The top 17 Indian pharmacy schools and colleges involved in pharmacological research have published from 77 to 440 papers each during 2003-2012. These 17 Indian pharmacy schools and colleges involved together have contributed $4.85 \%$ (2555 papers) in the cumulative publications output of India in pharmacological research. The publication profile of these 17 Indian pharmacy schools and colleges along with their research output, citations received and $\mathrm{HI}$ values are presented in Table 4.
The average publication productivity per college reported by the 17 Indian pharmacy schools and colleges was 150.29 and only six colleges have registered higher output than the group average. These are Manipal College of Pharmacy with 440 papers, followed by JSS College of Pharmacy (258 papers), LMM College of Pharmacy (254 papers), Al-Ameen College of Pharmacy (212 papers), Principla KM Kundnani College of Pharmacy (196 papers) and Bombay College of Pharmacy (177 papers).

The ACPP registered by the TP of these 17 Indian pharmacy schools and colleges was 2.03 (varying from 0.66 to 3.43) during 2003-2012 and eight colleges have registered higher citation impact than the group average. They are Rajiv Gandhi Academy of Pharmacy with ACPP of 3.43, followed by Bombay College of Pharmacy (3.05), BV Patel Pharmaceutical Education and Research Development PERD Centre (2.92), Bharati Vidyapeeth College of Pharmacy (2.82), RC Patel Institute of Pharmaceutical Research (2.49), VL College of Pharmacy (2.45), LM College of Pharmacy (2.09) and JSS College of Pharmacy (2.04).

The average HI registered by these 17 Indian pharmacy schools and colleges was 15.53 (varying from 5 to 29) during 2003-12 and eight colleges have registered higher $\mathrm{HI}$ value than the group average. They are Manipal College of Pharmacy with HI value of 29, followed by Bombay College of Pharmacy (26), JSS College of Pharmacy (23), LM College of Pharmacy (21), BV Patel Pharmaceutical Education and Research Development PERD Center (17), CL Baid Metha College of Pharmacy (17), Principla KM Kundnani College of Pharmacy (16) and Shri BM Shah College of Pharmacy (16). 
Gupta, et al.: High productivity pharmaceutical organizations in India

Table 4: Scientometric profile of top 17 Indian pharmacy schools and colleges in pharmacology, 2008-2012

\begin{tabular}{|c|c|c|c|c|c|c|c|c|}
\hline Name of the pharmacy schools and colleges & TP & TC & ACPP & $\mathrm{HI}$ & ICP & \%ICP & HCP & $\% \mathrm{HCP}$ \\
\hline Manipal College of Pharmaceutical Science & 440 & 865 & 1.97 & 29 & 36 & 8.18 & 1 & 0.23 \\
\hline JSS College of Pharmacy & 258 & 526 & 2.04 & 23 & 14 & 5.43 & 0 & 0.00 \\
\hline LM College of Pharmacy & 254 & 532 & 2.09 & 21 & 9 & 3.54 & 1 & 0.39 \\
\hline Al-Ameen College of Pharmacy & 212 & 315 & 1.49 & 14 & 10 & 4.72 & 0 & 0.00 \\
\hline Principal KM Kundnani College of Pharmacy & 196 & 346 & 1.77 & 16 & 15 & 7.65 & 1 & 0.51 \\
\hline Bombay College of Pharmacy & 177 & 539 & 3.05 & 26 & 10 & 5.65 & 1 & 0.56 \\
\hline CL Baid Metha College of Pharmacy & 139 & 209 & 1.50 & 17 & 10 & 7.19 & 2 & 1.44 \\
\hline Bharti Vidyapeeth College of Pharmacy & 107 & 302 & 2.82 & 15 & 1 & 0.93 & 1 & 0.93 \\
\hline AR Patel and GH Patel Institute of Pharmacy & 106 & 160 & 1.51 & 13 & 1 & 0.94 & 0 & 0.00 \\
\hline Sri BM Shah College of Pharmacy, Modesa & 93 & 152 & 1.63 & 16 & 0 & 0.00 & 0 & 0.00 \\
\hline KVS Rao Siddarth College of Pharmacy & 90 & 59 & 0.66 & 5 & 3 & 3.33 & 0 & 0.00 \\
\hline Rajiv Gandhi Academy of Pharmacy, Mathura & 86 & 295 & 3.43 & 13 & 2 & 2.33 & 0 & 0.00 \\
\hline $\begin{array}{l}\text { BV Patel Pharmaceutical Education and Research } \\
\text { Development PERD Centre }\end{array}$ & 86 & 251 & 2.92 & 17 & 9 & 10.47 & 1 & 1.16 \\
\hline PES College of Pharmacy & 79 & 139 & 1.76 & 9 & 1 & 1.27 & 0 & 0.00 \\
\hline RC Patel Institute of Pharmaceutical Research & 78 & 194 & 2.49 & 10 & 0 & 0.00 & 0 & 0.00 \\
\hline Bharti Vidyapeeth College of Pharmacy, Kolhapur & 77 & 106 & 1.38 & 8 & 4 & 5.19 & 0 & 0.00 \\
\hline VL College of Pharmacy, Raichur & 77 & 189 & 2.45 & 12 & 17 & 22.08 & 1 & 1.30 \\
\hline Total & 2555 & 5179 & 2.03 & 15.53 & 142 & 5.56 & 9 & 0.35 \\
\hline Total of the country & 52645 & & & & & & & \\
\hline Share of top 17 pharmacy school and colleges in India's total & 4.85 & & & & & & & \\
\hline
\end{tabular}

TP: Total papers, TC: Total citations, ICP: International collaborative papers, HCP: High cited papers, HI: h-index

The average share of ICP achieved by 17 Indian pharmacy schools and colleges involved in pharmacological research was $5.56 \%$ (varying from $0.0 \%$ to $22.08 \%$ ) during 2003-2012 and six colleges have achieved higher share of ICP than the group average. They are VL College of Pharmacy with ICP share of $22.08 \%$, followed by BV Patel Pharmaceutical Education and Research Development PERD Center (10.47\%), Manipal College of Pharmacy $(8.18 \%)$, Principla KM Kundnani College of Pharmacy (7.65\%), CL Baid Metha College of Pharmacy (7.65\%) and Bombay College of Pharmacy (5.65\%).

The average share of HCP achieved by 17 Indian pharmacy schools and colleges in pharmacological research was 0.35 (varying from $0.0 \%$ to $1.44 \%$ ) during 2003-2012 and seven colleges have achieved higher share of HCP than the group average. They are CL Baid Metha College of Pharmacy with HCP share of $7.65 \%$, followed by VL College of Pharmacy $(1.30 \%)$, Bharati Vidyapeeth College of Pharmacy $(0.93 \%)$, Bombay College of Pharmacy $(0.56 \%)$ and Principla KM Kundnani College of Pharmacy (0.51\%).

\section{Engineering colleges}

The top eight Indian engineering colleges involved in pharmacological research have published from 77 to 287 papers each during 2003-2012. These eight Indian engineering colleges together have contributed $2.59 \%(1362$ papers) in the cumulative publications output of India in pharmacological research. The publication profile of these eight Indian engineering colleges along with their research output, citations received and $\mathrm{HI}$ values are presented in Table 5 . The average publication productivity per college reported by the 8 Indian engineering colleges was 170.25 and only four colleges have registered higher output than the group average. These are Birla Institute of Technology and Science (BITS), Pilani with 287 papers, followed by the Institute of Technology (IT), BHU, Varanasi (239 papers), BITS, Mesra (221 papers) and Vellore Institute of Technology (VIT) (219 papers).

The ACPP registered by the TP of these eight engineering colleges was 2.96 (varying from 0.99 to 5.02) during 2003-2012 and two colleges have registered higher citation impact than the group average. They are BITS, Pilani with ACPP of 5.01 and IT, BHU, Varanasi (3.56).

The average HI registered by these eight engineering colleges was 15.62 (varying from 7 to 32) during 2003-2012 and four colleges have registered higher HI value than the group average. They are BITS, Pilani with HI value of 32, followed by IT, BHU, Varanasi (26), VIT (16) and BITS, Mesra (16).

The average share of ICP achieved by eight engineering colleges involved in pharmacological research was $11.09 \%$ (varying from 2.22\% to 21.25\%) during 2003-2012 and two colleges have achieved higher share of ICP than the group average. They are BITS, Pilani with ICP share of $22.25 \%$, followed by BITS, Mesra (14.48\%).

Journal of Young Pharmacists Vol 6 • Issue 2 • Apr-Jun 2014 
Gupta, et al:: High productivity pharmaceutical organizations in India

Table 5: Scientometric profile of top 8 engineering colleges in pharmacology, 2008-2012

\begin{tabular}{|c|c|c|c|c|c|c|c|c|}
\hline Name of the engineering colleges & TP & TC & ACPP & $\mathrm{HI}$ & ICP & \%ICP & HCP & $\% \mathrm{HCP}$ \\
\hline BITS, Pilani & 287 & 1438 & 5.01 & 32 & 61 & 21.25 & 3 & 1.05 \\
\hline IT, BHU, Varanasi & 239 & 850 & 3.56 & 26 & 23 & 9.62 & 4 & 1.67 \\
\hline BITS, Mesra & 221 & 502 & 2.27 & 16 & 32 & 14.48 & 1 & 0.45 \\
\hline VIT & 219 & 627 & 2.86 & 16 & 16 & 7.31 & 0 & 0.00 \\
\hline Gandhi Institute of Technology and Management, Hyderabad & 123 & 122 & 0.99 & 7 & 6 & 4.88 & 0 & 0.00 \\
\hline Meerut Institute of Engineering and Technology & 106 & 190 & 1.79 & 8 & 3 & 2.83 & 0 & 0.00 \\
\hline Sri Govindram Seksaria Institute of Technology and Science & 90 & 148 & 1.64 & 11 & 2 & 2.22 & 0 & 0.00 \\
\hline Anna University of Technology, Tiruchirappalli & 77 & 148 & 1.92 & 9 & 8 & 10.39 & 0 & 0.00 \\
\hline Total & 1362 & 4025 & 2.96 & 15.62 & 151 & 11.09 & 8 & 0.59 \\
\hline Total of the country & 52645 & & & & & & & \\
\hline Share of top 8 engineering colleges in India's total & 2.59 & & & & & & & \\
\hline
\end{tabular}

TP: Total papers, TC: Total citations, ICP: International collaborative papers, HCP: High cited papers, HI: h-index, BITS: Birla Institute of Technology and Science, IT: Institute of Technology, VIT: Vellore Institute of Technology

The average share of HCP achieved by eight engineering colleges in pharmacological research was 0.59 (varying from $0.0 \%$ to $1.67 \%$ ) during $2003-2012$ and two colleges have achieved higher share of HCP than the group average. They are BITS, Pilani with HCP share of 1.67\%, followed by IT, BHU, Varanasi (1.05\%).

\section{Medical colleges and hospitals}

The top 16 Indian medical colleges and hospitals involved in pharmacological research have published from 77 to 226 papers each during 2003-2012. These 16 Indian medical colleges and hospitals together have contributed $3.77 \%$ (1985 papers) in the cumulative publications output of India in pharmacological research. The publication profile of these 16 Indian medical colleges and hospitals along with their research output, citations received and HI values are presented in Table 6 . The average publication productivity per college reported by the 16 Indian medical colleges and hospitals was 124.06 and only six colleges have registered higher output than the group average. These are Kasturba Medical Colleges, Manipal with 226 papers, followed by the Institute of Medical Sciences, BHU, Varanasi (218 papers), Amala Cancer Hospital and Research Centre, Trissur (173 papers), University College of Medical Science, Delhi (153 papers), Christian Medical College, Vellore (150 papers) and Pandit Bhagwat Dayal Sharma Postgraduate Institute of Medical Sciences, Rohtak (142 papers).

The ACPP registered by the TP of these 16 Indian medical colleges and hospitals was 2.29 (varying from 1.52 to 4.16) during 2003-2012 and six colleges have registered higher citation impact than the group average. They are Sanjay Gandhi Postgraduate Institute of Medical Sciences, Lucknow with ACPP of 4.16, followed by Tata Memorial Hospital (3.58), Kasturba Medical Colleges, Manipal (2.61), Institute of Medical Sciences, BHU, Varanasi (2.43),
University College of Medical Science, Delhi (2.40) and Amala Cancer Hospital and Research Centre, Trissur (2.37).

The average HI registered by these 16 Indian medical colleges and hospitals was 15.06 (varying from 6 to 30) during 2003-2012 and seven colleges have registered higher $\mathrm{HI}$ value than the group average. They are Kasturba Medical Colleges, Manipal with HI value of 30, followed by Amala Cancer Hospital and Research Center, Trissur (30), Institute of Medical Sciences, BHU, Varanasi (24), Sanjay Gandhi Postgraduate Institute of Medical Sciences, Lucknow (19), Christian Medical College, Vellore (19), University College of Medical Science, Delhi (17) and Jawaharlal Nehru Medical College, Aligarh (16).

The average share of ICP achieved by 16 Indian medical colleges and hospitals involved in pharmacological research was $8.51 \%$ (varying from $0.00 \%$ to $16.00 \%$ ) during 2003-2012 and eight colleges have achieved higher share of ICP than the group average. They are Christian Medical College, Vellore with ICP share of $16.00 \%$, Medical College and Hospital, Kolkata (14.29\%), Sanjay Gandhi Postgraduate Institute of Medical Sciences, Lucknow (12.99\%), Tata Memorial Hospital (12.50\%), Institute of Medical Sciences, BHU, Varanasi (12.39\%), Kasturba Medical College, Mangalore (12.04\%), Kasturba Medical Colleges, Manipal (9.73\%) and Jawaharlal Nehru Medical College, Aligarh (9.01\%).

The average share of HCP achieved by 16 Indian medical colleges and hospitals in pharmacological research was 0.35 (varying from $0.0 \%$ to $2.60 \%$ ) during 2003-2012 and six colleges have achieved higher share of HCP than the group average. They are Sanjay Gandhi Postgraduate Institute of Medical Sciences, Lucknow with HCP share of 2.60\%, followed by Medical College and Hospital, Kolkata (1.30\%), Jawaharlal Nehru Medical College, Aligarh (0.90\%), University College of Medical Science, Delhi (0.65\%), 
Amala Cancer Hospital and Research Center, Trissur $(0.58 \%)$ and Kasturba Medical Colleges, Manipal (0.44\%).

\section{Industrial firms}

The top nine Indian industrial firms involved in pharmacological research have published from 31 to 432 papers each during 2003-2012. These nine Indian industrial firms together have contributed $1.78 \%$ (936 papers) in the cumulative publications output of India in pharmacological research. The publication profile of these nine Indian industrial firms along with their research output, citations received and $\mathrm{HI}$ values are presented in Table 7. The average publication productivity per college reported by the nine Indian industrial firms was 104 and only three industrial firms have registered higher output than the group average. These are Dr. Reddy's Laboratories, Hyderabad with 432 papers, followed by Ranbaxy Research Laboratories, Gurgaon (156 papers) and Cadilla Healthcare Ltd. (116 papers).

The ACPP registered by the TP of these nine Indian industrial firms was 3.35 (varying from 2.06 to 4.46) during 2003-2012 and two industrial firms have registered higher citation impact than the group average. They are Ranbaxy Research Laboratories, Gurgaon with ACPP of 4.46, followed by Dr. Reddy's Laboratories, Hyderabad (3.43).

The average HI registered by these nine Indian industrial firms was 14.89 (varying from 8 to 29) during 2003-2012 and three industrial firms have registered higher HI value than the group average. They are Dr. Reddy's Laboratories,

Table 6: Scientometric profile of top 16 medical colleges and hospitals in pharmacology, 2008-2012

\begin{tabular}{|c|c|c|c|c|c|c|c|c|}
\hline Name of the medical colleges and hospitals & TP & TC & ACPP & $\mathrm{HI}$ & ICP & \%ICP & HCP & $\% \mathrm{HCP}$ \\
\hline Kasturba Medical Colleges, Manipal & 226 & 590 & 2.61 & 30 & 22 & 9.73 & 1 & 0.44 \\
\hline Institute of Medical Sciences, BHU, Varanasi & 218 & 530 & 2.43 & 24 & 27 & 12.39 & 0 & 0.00 \\
\hline Amala Cancer Hospital and Research Centre, Trissur & 173 & 410 & 2.37 & 30 & 9 & 5.20 & 1 & 0.58 \\
\hline University College of Medical Science, Delhi & 153 & 367 & 2.40 & 17 & 10 & 6.54 & 1 & 0.65 \\
\hline Christian Medical College, Vellore & 150 & 318 & 2.12 & 19 & 24 & 16.00 & 0 & 0.00 \\
\hline $\begin{array}{l}\text { Pandit Bhagwat Dayal Sharma Postgraduate Institute of Medical } \\
\text { Sciences, Rohtak }\end{array}$ & 142 & 216 & 1.52 & 9 & 0 & 0.00 & 0 & 0.00 \\
\hline Jawaharlal Nehru Medical College, Aligarh & 111 & 245 & 2.21 & 16 & 10 & 9.01 & 1 & 0.90 \\
\hline Kasturba Medical College, Mangalore & 108 & 231 & 2.14 & 11 & 13 & 12.04 & 0 & 0.00 \\
\hline Maulana Azad Medical College, Delhi & 102 & 197 & 1.93 & 10 & 6 & 5.88 & 0 & 0.00 \\
\hline Dayanand Medical College and Hospital, Ludhiana & 99 & 167 & 1.69 & 6 & 2 & 2.02 & 0 & 0.00 \\
\hline Madras Medical College & 96 & 176 & 1.83 & 9 & 3 & 3.13 & 0 & 0.00 \\
\hline Tata Memorial Hospital & 88 & 315 & 3.58 & 14 & 11 & 12.50 & 0 & 0.00 \\
\hline National Institute of Medical Sciences, Jaipur & 86 & 139 & 1.62 & 6 & 8 & 9.30 & 0 & 0.00 \\
\hline Lady Harding Medical College, Delhi & 79 & 144 & 1.82 & 8 & 3 & 3.80 & 0 & 0.00 \\
\hline Medical College and Hospital, Kolkata & 77 & 171 & 2.22 & 13 & 11 & 14.29 & 1 & 1.30 \\
\hline Sanjay Gandhi Postgraduate Institute of Medical Sciences, Lucknow & 77 & 320 & 4.16 & 19 & 10 & 12.99 & 2 & 2.60 \\
\hline Total & 1985 & 4536 & 2.29 & 15.06 & 169 & 8.51 & 7 & 0.35 \\
\hline Total of the country & 52645 & & & & & & & \\
\hline Share of top 16 medical colleges and hospitals in India's total & 3.77 & & & & & & & \\
\hline
\end{tabular}

TP: Total papers, TC: Total citations, ICP: International collaborative papers, HCP: High cited papers, HI: h-index

Table 7: Scientometric profile of top 9 industrial firms in pharmacology, 2008-2012

\begin{tabular}{lcccccccc}
\hline Name of the industrials & TP & TC & ACPP & HI & ICP & $\%$ ICP & HCP & $\%$ HCP \\
\hline Dr. Reddy's Laboratories, Hyderabad & 432 & 1483 & 3.43 & 29 & 27 & 6.25 & 0 & 0.00 \\
Ranbaxy Research Laboratories, Gurgaon & 156 & 695 & 4.46 & 25 & 20 & 12.82 & 1 & 0.64 \\
Cadilla Healthcare Ltd. & 116 & 377 & 3.25 & 17 & 13 & 11.21 & 0 & 0.00 \\
Suven Life Sciences Ltd. & 64 & 165 & 2.58 & 14 & 0 & 0.00 & 0 & 0.00 \\
Matrix Laboratories Ltd. & 36 & 110 & 3.06 & 11 & 1 & 2.78 & 0 & 0.00 \\
Pirmal Life Sciences Ltd. & 35 & 105 & 3.00 & 8 & 2 & 5.71 & 0 & 0.00 \\
Jubilant Biosys Ltd. & 34 & 72 & 2.12 & 9 & 1 & 2.94 & 0 & 0.00 \\
Natural Remedies Pvt. Ltd. & 32 & 68 & 2.13 & 10 & 1 & 3.13 & 0 \\
Syngene International Ltd. & 31 & 64 & 2.06 & 11 & 16 & 51.61 & 0 \\
Total & 936 & 3139 & 3.35 & 14.89 & 81 & 8.65 & 1 \\
Total of the country & 52645 & & & & & 0.00 \\
Share of top 9 industrial enterprises in India's total & 1.78 & & & & & &
\end{tabular}

TP: Total papers, TC: Total citations, ICP: International collaborative papers, HCP: High cited papers, HI: h-index 
Hyderabad with HI of 29, followed by Ranbaxy Research Laboratories, Gurgaon (25) and Cadilla Healthcare Ltd. (17).

The average share of ICP achieved by nine Indian industrial firms involved in pharmacological research was $8.65 \%$ (varying from $0.00 \%$ to $51.61 \%$ ) during $2003-2012$ and three industrial firms have achieved higher share of ICP than the group average. They are Syngene International Limited with ICP share of $51.61 \%$, Ranbaxy Research Laboratories, Gurgaon (12.82\%) and Cadilla Healthcare Ltd. (11.21\%).

The average share of HCP achieved by one Indian industrial firms in pharmacological research was 0.11 (varying from $0.0 \%$ to $0.64 \%$ ) during $2003-2012$ and one industrial firm have achieved higher share of HCP than the group average. It is Ranbaxy Research Laboratories, Gurgaon with HCP share of $0.64 \%$.

\section{CONCLUSION}

The top 110 high productivity organizations in India collectively produced 28,660 papers, which constitute $54.44 \%$ share of the total publication output of India in pharmacology research during 2008-2012. The output of these 110 high productivity Indian organizations individually varied from 31 to 1467 papers, with an average productivity per organization as 260.54 . The research impact as measured by citations per paper of these 110 most productive Indian organizations varied from 0.66 to 7.61, with an average of 3.72 .

Institutional models of funding for research in pharmacology research do seem to influence research performance in India. Research institutions (the first model of institutional funding in India) ranked first in ACPP (5.02) and share of HCP $(0.96 \%)$, second in publication productivity per institute (303.09) and fourth rank in share of ICP (10.07\%). INIs (second model of institutional funding in India) ranked first in share of ICP $(24.42 \%)$, second rank in ACPP (4.24), third rank in average productivity per institute (223.83) and HI (24.42), and fourth rank in share of HCP $(0.41 \%)$. Universities (third model of institutional funding) ranked first in publication productivity per university (486.6) and HI (30.68), third rank in ACPP (3.56), share of ICP $(10.88 \%)$ and share of HCP $(0.56 \%)$. Engineering colleges (fourth model of institutional funding) ranked second in share of ICP $(11.09 \%)$ and share of HCP $(0.59 \%)$, fourth in average productivity per college (170.25), and fifth in ACPP (2.96) and HI (15.62). Industrial enterprises (fifth model of institutional funding) ranked fourth in ACPP (3.35), fifth in share of ICP $(8.65 \%)$ and seventh in average productivity per firm (104), HI (14.89) and share of HCPs $(0.11 \%)$. Medical colleges and hospitals (sixth model of institutional funding) ranked sixth in average productivity per college (124.06), ACPP (2.29), HI (15.06), share of ICP $(8.51 \%)$ and share of HCP (0.35). Pharmacy schools and colleges (seventh model of institutional funding) ranked fourth in average productivity per college (170.25), fifth in HI (15.53) and seventh in ACPP (2.03), ICP (5.56\%) and share of HCP $(0.35 \%)$.

The study indicates that research institutes, INIs and universities model of funding for research are comparatively more effective in giving better performance in terms of quantity and quality. In contrast, pharmacy schools and colleges, engineering colleges, medical colleges and hospitals and industrial firms models of funding appear to be comparatively weaker. It is suggested that India should develop appropriate institutional mechanism for overall monitoring, coordination and management of pharmaceutical research in India. It should address issues such as setting up research facilities common to scientists and teachers from several organizations, allocation of funds for priority national research and for encouraging creativity among young scholars and identification of the critical support required for setting up specialized research facilities.

\section{REFERENCES}

1. Careers in Pharmacy. Available from: http://www.icbse.com/careers/ careers-in-pharmacy. [Last accessed on 2014 Jan 15].

2. Ahila M, Nagarajan M. Research publication trends in pharmaceutical research: A bibliometric study. Libr Progrss (Int) 2011;31:79-89.

3. Kaur H, Gupta BM. Indian contribution in pharmacology, toxicology \& pharmaceutics during 1998-2007: A scientometric analysis. Collnet J Scientometrics Inf Manage 2009;3:1-9.

4. Gupta BM, Kaur H. Ranking of Indian pharmaceutical institutions for their research performance during 2000-2009. Int J Pharm Appl 2011;2:99-104. 